\title{
El Perí y las Tentativas de Concordato
}

\author{
Por el Presbitero HUCOO GARAYCOA $\left(^{*}\right)$
}

El Perú es un Estado "Concordatista" de facto, ya que no ha celebrado ninzún Concordato con la.Santa Sede (1).

En el Congreso se ha aludido algunas veces al Patronato como consecuencia de un Concordato, como lo hizo el Dr. Fidel Olivas Escudero en 1896, al referirse a la ley de Cofradias, o el Señor Buenaño, cuando en 1941 propuso la nacionalización del clero, pero estas aluciones se basan en que se toma la Bula "Preclara inter Beneficia" como un concordato.

Las primeras manifestaciones de un deseo de Concordato las encontramos en los primeros días de vida republicana y es el Libertador Simón Bolívar quien expresó su deseo de realizarlo, y en 1835 el Ministro de Relaciones Exteriores refiriéndose a este deseo del Libertador se expresaba así: "Este principio de comunicación tan satisfactorio para la Iglesia y de tanto consuelo a los pueblos religiosos asegurará probablemente un Concordato entre la República y la Santa Sede" (2).

Este deseo de arreglar un concordato se encuentra expresado en las constitúciones de los años 1828, hasta la del año 1933.

Al concederse el Pase a la Bula "Ex sublime Petri Specula" por la cuai se creaba las diócesis de Chachapoyas en reemplazo de la de Mainas, el gobierno hacía reclamo de no haberse en ella reconocido el Patronato Nacional y "pues (la Nación peruana) desea vehementemente arreglar el ejercicio del Patronato; celebrando a este fin Concordatos que no le han permitido hasta ahora las visicitudes del país..." (3).

(*) Doctor en Derecho Canónico, Universidad Lateranense de Roma.- Catedrático de Derecho Canónico y Público Eclesiástico en la Facultad de Derecho de la Pontificia Universidad Católica; Director del Centro Nacional de Vocaciones.

(1) Visión del Perú en el Siglo XX, Vol. II, pg. 482.

(2) Memoria del Ministro de Relaciones Exteriores al Congreso Canstituyente del 12 de febrero de 1825, se refería a las relaciones con el Vicario Apostólico Mons. Muzi.

(3) Pase a la Bula "Ex sublime Petri Specula" del 23 de setiembre de 1844. Aranda - Tratados del Perú - Vol. XI pág. 85. 
Las primeras Instrucciones para un concordato son dadas en el año 1849, cuando aún no había representante del Perú en Roma.

Las primeras instrucciones dadas por el Senado de acuerdo a la Constitución (1) para un Concordato fueron pasadas al Presidiente de la República para que este las ejecutara, y eran:

1)-Gestionar el reconocimiento del Patronato Nacional en los mismos términos que lo ejerció el Rey de España.

2)-Que los Obispos electos pudieran gobernar las Iglesias antes de recibir las Bulas de institución y sólo con la representación y nota de ruego y encargo a los Cabildos en Sede Vacante.

3)-La reducción de los días de fiesta para toda la República en los mismos términos que se había concedido a la Arquidiócesis.

4)-Que se amplíen las facultades de disponer a los Obispos, en todos los impedimentos de matrimonio.

5)-Conseguir la dependencia total de los regulares a sus inmediatos, y que los Ordinarios puedan por si solos conceder la exclaustración a los regulares de ambos sexos, con causa fundada y por motivos de concienca que aleguen.

6) - La facultad de reducir "Extra Synodum servatis servandis" el número de misas dispuesto por los fundadores de Capellanías y Obras Fias.

Afirma la mencionada nota que "Es inconcuso que una nación católica, en la actual disciplina vigente de la Iglesia, no puede dejar de entrar en relaciones con la Santa Sede para arreglar los negcios graves que sólo ella puede resolver. Reconocer el Primado de Jurisdicción del Romano Pontífice, lo que es de fé, y disputarle de hecho, el ejercicio de varias facultades que la Iglesia Católica reconoce existir hoy en sólo el Romano Pontífice, queriendo hacerlas ejercer por los Obispos sin su consentimiento, es negar en la práctica ese Primado que se confiesa en la teoría. Prescindir absolutamente del Romano Pontífice, en materias que son de su primitiva inspección y negarse a tratar nada con él, sería romper el vínculo de la unidad que liga a todos los fieles del mundo con la cabeza visible de la Iglesia" (2).

Con respecto al hecho de que los Obispos tomen Posesión de la Diócesis con la sola presentación por el gobierno sin esperar las Bulas, hace notar el Dictamen, que esto era una costumbre del antiguo régimen español, ,y, que venía como una consecuencia de las teorías regalistas y que algunos apoyaban en el consentimiento tácito del Papa, que ignorando la mencionada práctica, no reclamaba contra ella (3).

(1) Según el artículo 41 de la Constitución de 1839.

(2) Dictamen de la Corte Suprema sobre las Instrucciones dadas por el Senado al Presidente de la República para realizar un Concordato con la Santa Sede, del 4 de noviembre 1847 - Aranda_ Tratados del Perú - Vol. XI, pág. 144.

(3) Idem. (ver påg. 3). 
Con el informe, y al Pase al Ejecutivo se abría el camino a un acuerdo con Roma, pero, no se había nombrado ningún representante en Roma y las Instrucciones permanecen archivadas, hasta que el 10 de noviembre de 1854. Posteriormente el Senado comunica al Ministro de Relaciones Exteriores que se revocaban las instrucciones, y esto sucedía pocos meses antes del envio de un representante ante la Santa Sede.

Visto el éxito de las gestiones de Bartolomé Herrera ante la Santa Sede y lo favorablemente dispuesta que se encontraba ésta a realizar un acuerdo con el Perú, el Ejecutivo en el cual residía por nueva Constitución el poder de dar las instrucciones para un Concordato, emana nuevas instrucciones que no son aprobadas por el Senado el cual recomienda que se usen las del año 1849, habiéndoselas enviado a Bartolomé Herrera, este no acepta negociar un concordato en los términos que se piden. Ya que casi todas las cosas que se pedían en dichas instrucciones habían sido concedidas por Su Santidad en la forma de Rescriptos y Resoluciones, excepción hecha del reconocimiento del Patronato y de la Jurisdicción plena de los Obispos en las diócesis a la sola presentación por el gobierno, cosas que ciertamente Roma no aceptaría, y no se realizó un concordato.

Siendo Ministro del Perú ante la Santa Sede el Dr. Luis Mesones (1) pide instrucciones para un posible concordato, ya que había interés de parte de la Santa Sede en que se realizara y se le contesta que: "El gobierno coincide con el interés de la Santa Sede, respecto al definitivo arreglo de las relaciones eclesiásticas entre ambos Estados y está dispuesto a cumplir con el precepto que le impone el artículo 134 de la Constitución (2), procediendo a la celebración de un Concordato. Más, para que esto se realice es necesario reunir los antecendentes y datos que existen en el Ministerio y solicitar del Senado las instrucciones respectivas. Así se verificará, y oportunamente, recibirá Ud. las órdenes que el gobierno debe trasmitirle para terminar aquel negociado, teniendo presente, también, las indicaciones hechas por Ud." (3). Las instrucciones no llegaron y así nuevamente no se llegó a un Concordato.

Siendo Ministro del Perú ante la Santa Sede y gobernando la Iglesia Universal Su Santidad Pío IX, este dió la Bula "Preclara Inter Beneficia" que otorgaba a perpetuidad el Patronato en la persona del Presidente de la República y sus sucesores".

“...Peruvianae Republicae Praesidi, ejusque succesoribus pro tempore existentibus, qui catholicam fidem profiteantur indulgere deerimus; prout Aplica. Autoritate indulgemus; uti in territorio suae Reipublicae fruit possint eo PATRONATUS JURE quo ante Peruviam regionem a dictione hispánica sejuntam, Catholici reges Hispaniarum e indulgentia Sedis Aplicae ibi fruebantur, ea tamen conditione et lege, ut ea quae dotis nomine assignata

(1) El año de 1861

(2) La Constitución del año 1860.

(3) Comunicación del Ministerio de Relaciones Exteriores al Ministro ante la Santa Sede - Archivo de la Embajada del Pexú ante la Santa Sede - año 1861 
sunt tum Clero, tum Sacro Ministerio et Culti excercendo in diocessibus territori praedicti Reipublicae serventur integre..." (1).

Se puede considerar esta Bula un verdadero Concordato? En el Volumen de Tratados, Convenciones y Acuerdos Vigentes entre el Perú y Otros. Estados, la Bula aparece presentada como un verdadero Concordato contenido implícitamente hasta el momento en que el Gobierno de Nicolás de Piérola concedió concedió el EXEQUATUR a la Bula el 27 de enero 1890 .

El Moroni en stis dos ediciones de Racolta di Concordati" de 1919 y 1954 no la incluye, lo mismo que Perugini en su "Concordata Vigencia de 1950", sólo ha sido incluido en el "Supplemento alla Racolta di Concordati" del Moroni del año 1953.

En realidad la Bula cumple con las condiciones que pone Van Hove en su definición de Concordatos? "... Concesio sive conventio auctoritatis ecclesiasticae et auctoritatis civilis, qua ordinatur relationis inter Essclesiam et Statum circu materiam aliqua ratione utramque potestatem concernentem". (2) presentando este acuerdo a dos partes una de parte del Romano Pontífice y otra de parte del Jefe del Estado.

Pudiéndose hacer en una triple forma:

1) Duorum documentoruum.

2) IN FORMA BULLAE: In Forma Bullae hand pauca sunt edita concordata, speciatin saeculo $\mathrm{XV}$ in Concilio Constantinensi et Saeculo $\mathrm{XIX}$ in variis regionibus Germanie.

3) In forma conventionis, que es la forma moderna

Esta misma división la presenta Werns Francisco Javier (3) en quanto a la división de los Concordatos:

1) Dos declaraciones o leyes, una de parte del Papa y Otra de parte. del Estado, Como por Ej. El Concordato de Worms. Privilegio del Papa de una parte (Calixto II) y Precepto de parte de Enrique IV.

2) Pacto bilateral, como el realizado entre Francisco I y León X por Notas diplomáticas.

Ottaviani en su Instituciones Iuris Publici Eclesiástico (4) presenta. también tres formas para los concordatos:

1) En forma de tratados

2) Por promulgación de una Bula

3) Por una forma de doble declaración

(1) Copia auténtica en Archivo de la Embajada del Perú ante la Santa Sede-Rom.

(2) Van Hove, Prolegomena ad comentarium Lovaniense. In Cotem Iruis Canenici. Mechlinaes - Roma 1945, pág. 83.

(3) Ius Decretalium Tomo I Introductio -in lus Decretalium Roma, 1905, nse... Pg. 225, ss.

(4) Obra citada, 1960 - Roma, Tomo II Pág. 253 y ss. 
En realidad aún cuando en apariencia la Bula parece que se pueda incluir en la forma de un concordato, ella es solamente para reglamentar un punto de controversia como era el hecho del Patronato, que de facto se venía ejerciendo por los gobernantes peruanos, basándose en una sucesión del Patronato de los Reyes de España, pero no abarca todos los puntos que modernamente abarcan los concordatos y esto mismo se hace sentir aún más por el hecho de que el Perú después del otorgamiento de la Bula continuó en proyectos para la realización de un concordato.

Es opinión del Padre Capello (1) que una bula toma la forma de Concordato cuando esta toca un punto de derecho espiritual o anejo a uno espiritual como lo es el de la presentación de los Obispos y la dotación de las Iglesias. El solo hecho de la bula, en realidad no se puede aceptar como un concordato ya que en ese caso serían muchos los concordatos existentes en esta forma y que la Iglesia no los considera como tales.

Si vemos el asunto sobre el aspecto de que a la dación de la Bula se siguió un 'P'ase y Exequatur por el Gobierno de Nicolás de Piérola, posteriormente fueron declarados nulos y todos los actos de su gobierno alegando inconstitucionalidad, y jamás hasta nuestros días dicha bula ha obtenido un nuevo "Pase y Exequatur, aún cuando el Gobierno continúa haciendo uso del privilegio del Patronato, y las ayudas del Estado son en todo conforme a lo dispuesto por la Bula, lo mismo en lo que respecta a la dotación y ayuda por parte del Estado a la Iglesia.

La situación real del Perú es la de un país que ha buscado siempre arreglar su situación con la Santa Sede por medio de un concordato. Cuando había Embajador en Roma no habían instrucciones y cuando habían instrucciones no había Embajador. La última tentativa de Concordato fué en tiempos recientes cuando ocupaba la Suprema Magistratura el Dr. José Luis Bustamante y Rivero y era Nuncio de Su Santidad en Lima Mons. Arrigoni, pero la oposición de las Cámaras sobre la abolición de la Ley del Divorcio, condición que exigía la Santa Sede, y la caída del Presidente determinaron qué el Perú siguiera sin Concordato hasta nuestros días.

(1) Capello - Summa luris Publici Eclesiastici, Roma, 1954, Págs. 253-255. 